\title{
Low Tidal Volume Positive End-Expiratory Pressure versus High Tidal Volume Zero-Positive End-Expiratory Pressure and Postoperative Pulmonary Functions in Robot-Assisted Laparoscopic Radical Prostatectomy
}

\author{
Murat Haliloglu ${ }^{a}$ Beliz Bilgilia Mehtap Ozdemir $^{b}$ Tumay Umuroglu ${ }^{a}$ \\ Nurten Bakan ${ }^{b}$

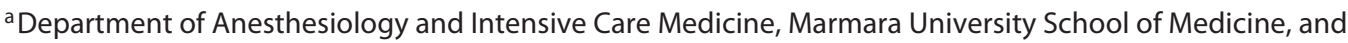 \\ bumraniye Education and Research Hospital, Istanbul, Turkey
}

\section{Significance of the Study}

- In this study, patients ventilated with a high $\mathrm{V}_{\mathrm{T}}$ and ZEEP were more prone to the unwanted effects of combined sT positioning and pneumoperitoneum compared to patients ventilated with a low $\mathrm{V}_{\mathrm{T}}$ and a moderate end-expiratory pressure. The adaptation of a low $\mathrm{V}_{\mathrm{T}}$ with moderate PEEP and lung protective ventilation in patients undergoing RALP was a major factor in outcome improvement. This finding could be extended to patients undergoing RALP.

\section{Keywords}

Pneumoperitoneum · Steep Trendelenburg · Low tidal volume $\cdot$ Positive end-expiratory pressure $\cdot$ Pulmonary function $\cdot$ Robot-assisted surgery

\begin{abstract}
Objective: The aim was to compare the effects of low tidal volume $\left(\mathrm{V}_{T}\right)$ and moderate positive end-expiratory pressure (PEEP) with high $\mathrm{V}_{T}$ and zero end-expiratory pressure (ZEEP) on postoperative pulmonary functions and oxygenation in patients undergoing robot-assisted laparoscopic radical prostatectomy. Subjects and Methods: Forty-four patients
\end{abstract}

\section{KARGER}

E-Mail karger@karger.com www.karger.com/mpp

\section{The Author(s) \\ Published by S. Karger AG, Basel \\ Karger \\ Open access}

This is an Open Access article licensed under the Creative Commons Attribution-NonCommercial-4.0 International License (CC BY-NC) (http://www.karger.com/Services/OpenAccessLicense), applicable to the online version of the article only. Usage and distribution for commercial purposes requires written permission. were randomized into low $\mathrm{V}_{\mathrm{T}}$-PEEP and high $\mathrm{V}_{\mathrm{T}}$-ZEEP groups. The patients were ventilated with a $V_{T}$ of $6 \mathrm{~mL} / \mathrm{kg}$ and $8 \mathrm{~cm}$ $\mathrm{H}_{2} \mathrm{O}$ PEEP in the low $V_{T}$-PEEP group and $a V_{T}$ of $10 \mathrm{~mL} / \mathrm{kg}$ and $0 \mathrm{~cm} \mathrm{H}_{2} \mathrm{O}$ PEEP in the high $\mathrm{V}_{\mathrm{T}}$-ZEEP group. Preoperative and postoperative spirometric measurements were done and chest $\mathrm{X}$-rays were evaluated using the radiological atelectasis score (RAS). $p<0.05$ was considered statistically significant. Results: The intraoperative and postoperative arterial partial pressure of oxygen and arterial oxygen saturation values were significantly higher in the low $\mathrm{V}_{\mathrm{T}}$-PEEP group than in the high $\mathrm{V}_{\mathrm{T}}$-ZEEP group. At all times, the arterial-to-alveolar oxygenation gradients were significantly lower in the low $\mathrm{V}_{T^{-}}$ PEEP group than in the high $\mathrm{V}_{\mathrm{T}}$ ZEEP group. Preoperative 
RAS were similar in both groups, but the postoperative RAS was significantly lower in the low $\mathrm{V}_{\mathrm{T}}$-PEEP group $(p<0.001)$. Forced vital capacity, forced expiratory volume in $1 \mathrm{~s}$, and peak expiratory flow rate recorded postoperatively were significantly lower in the high $\mathrm{V}_{\mathrm{T}}$-ZEEP group $(p<0.001)$. Conclusions: Postoperative pulmonary functions were less impaired in patients ventilated with a $V_{T}$ of $6 \mathrm{~mL} / \mathrm{kg}$ and $8 \mathrm{~cm}$ $\mathrm{H}_{2} \mathrm{O}$ PEEP than in patients ventilated with a $V_{T}$ of $10 \mathrm{~mL} / \mathrm{kg}$ and ZEEP.

(c) 2017 The Author(s)

Published by S. Karger AG, Basel

\section{Introduction}

Prostate cancer is the sixth most common cancer in the world and a frequent cause of cancer-related deaths [1]. Radical prostatectomy (RP) is an effective surgical treatment for localized prostate cancer; robot-assisted laparoscopic RP (RALP) is the newest, most minimally invasive and technologically advanced surgical alternative [2]. In the last 10 years, RALP has been the most extensively used procedure for removal of prostate cancer, and the frequency of RALP has increased from 1 to approximately $70 \%[3,4]$. The advantages of RALP are the easy access to difficult anatomical structures through smaller incisions, decreased blood loss and transfusion requirements, less pain, and the short hospital stay [5]. However, RALP has several problems due to pneumoperitoneum and steep Trendelenburg (sT) positioning [6]. Pneumoperitoneum and sT positioning result in cranial displacement of the diaphragm, reducing the functional residual capacity and compliance and increasing airway resistance and ventilation-perfusion mismatch [7]. Hence, the aim of this study was to compare the effects of low tidal volume $\left(V_{\mathrm{T}}\right)$ and moderate positive endexpiratory pressure (PEEP) with high $\mathrm{V}_{\mathrm{T}}$ and zero endexpiratory pressure (ZEEP) on postoperative pulmonary functions and oxygenation during prolonged pneumoperitoneum and sT positioning in patients undergoing RALP.

\section{Subjects and Methods}

This prospective, observational clinical trial was carried out at the Umraniye Education and Research Hospital, Istanbul, Turkey, between January and November 2011. The Institutional Review Board approved this study, written informed consent was obtained from patients, and this study was conducted in accordance with Declaration of Helsinki including current revisions and Good
Clinical Practice guidelines. A total of 50 consecutive patients with American Society of Anesthesiologists (ASA) physical status I or II undergoing RALP were enrolled into this study. The patients were assigned to either a low $\mathrm{V}_{\mathrm{T}}$-PEEP group or a high $\mathrm{V}_{\mathrm{T}}$-ZEEP group using the sealed-envelope system. Patients in the low $\mathrm{V}_{\mathrm{T}^{-}}$ PEEP group were ventilated with a $V_{T}$ of $6 \mathrm{~mL} / \mathrm{kg}$ ideal body weight and $8 \mathrm{~cm} \mathrm{H}_{2} \mathrm{O}$ PEEP, while patients in the high $\mathrm{V}_{\mathrm{T}}$-ZEEP group were ventilated with a $V_{T}$ of $10 \mathrm{~mL} / \mathrm{kg}$ ideal body weight and $0 \mathrm{~cm} \mathrm{H}_{2} \mathrm{O}$ PEEP in group. The exclusion criteria were: cardiovascular and respiratory diseases (forced expiratory volume in $1 \mathrm{~s}$ $\left[\mathrm{FEV}_{1}\right]<50 \%$ of the predicted value and forced vital capacity [FVC] $<50 \%$ of the predicted value), acute asthma exacerbation, obesity (BMI >40), and home oxygen therapy. Fifty-five patients were assessed for eligibility to be included in this study. However, 50 patients gave written informed consent to participate. Four patients were not able to undergo preoperative spirometric testing. Two patients could not undergo postoperative spirometric testing. In total, 44 participants were included in the analysis, i.e., 24 in the low VT-PEEP group and 20 in the high VT-ZEEP group. A power analysis showed that 20 patients per group were required for with a power of $80 \%$ and a $p$ value of 0.05 .

Preoperative spirometric measurements were performed using the standards of the American Thoracic Society with a Microlab 3000 series bedside spirometer (Micro Medical Ltd, Rochester, UK) [8]. All measurements were performed in the supine position with the head elevated $30^{\circ}$. Diet was restricted to only clear liquids 1 day prior to surgery, and ranitidine orally and low-molecularweight heparin subcutaneously were administered the evening before the surgery. No premedication was given.

In the operating room, ectrocardiography, invasive arterial blood pressure, pulse oximetry, bispectral index, end-tidal anesthetic gas, and end-tidal carbon dioxide $\left(\mathrm{ETCO}_{2}\right)$ monitorings were performed. Anesthesia was induced intravenously with remifentanil $1 \mu \mathrm{g} \cdot \mathrm{kg}^{-1}$, propofol $2-2.5 \mathrm{mg} \cdot \mathrm{kg}^{-1}$, and rocuronium 0.6 $\mathrm{mg} \cdot \mathrm{kg}^{-1}$. Following endotracheal intubation, anesthesia was maintained with desflurane $4-6 \%$ (end-tidal concentration) and remifentanil $0.1-0.3 \mu \mathrm{g} \cdot \mathrm{kg}^{-1} \cdot \mathrm{min}^{-1}$ and adjusted to keep BIS values between 40 and $60 \%$. Rocuronium was administered to maintain deep neuromuscular block according to clinical need. The train-of-four ratio was used for neuromuscular block monitoring. A ratio greater than 0.9 was required prior to extubation. Volumecontrolled ventilation (Dräger Medical, Lübeck, Germany) was delivered with an inspiratory-to-expiratory time ratio of $1: 2$ at an inspired oxygen fraction of 0.5 . Air was used as a carrier gas. The respiratory rate was adjusted to maintain $\mathrm{ETCO}_{2}$ between 35 and $40 \mathrm{~mm} \mathrm{Hg}$, and plateau pressures were kept lower than $30 \mathrm{~cm} \mathrm{H}_{2} \mathrm{O}$. No recruitment maneuvers were performed.

At the end of the surgery, patients were extubated when fully awake. Postoperative intravenous patient-controlled analgesia with morphine chloride was provided. Postoperative pain was evaluated using a numerical rating scale (NRS) of $0-10$ as follows: no pain, 0 ; mild pain, $0-2$; milder pain, 3-4; and severe pain, 5-10. Intramuscular diclofenac sodium was administered as a rescue analgesic when the NRS score was $\geq 3$.

Patients were placed on an egg crate mattress that was attached to the bed, and their lower extremities were placed in padded lithotomy stirrups. Shoulder braces covered with foam gel pads were used as additional safety devices to prevent brachial plexus or ulnar nerve injury. Pneumoperitoneum was induced with carbon dioxide, and the intra-abdominal pressure was set at $10-20 \mathrm{~mm}$ 
Table 1. Patient characteristics and operative data

\begin{tabular}{|c|c|c|c|c|}
\hline & & $\begin{array}{l}\text { Low } \mathrm{V}_{\mathrm{T}} \text {-PEEP } \\
(n=24)\end{array}$ & $\begin{array}{l}\text { High } \mathrm{V}_{\mathrm{T}}-\mathrm{ZEEP} \\
(n=20)\end{array}$ & $p$ value \\
\hline \multicolumn{2}{|l|}{ Age, years } & $62.17 \pm 6.54$ & $61.75 \pm 4.47$ & 0.59 \\
\hline \multicolumn{2}{|l|}{ BMI } & $28.23 \pm 3.35$ & $28.50 \pm 4.24$ & 1.0 \\
\hline \multicolumn{2}{|c|}{ Duration of the operation, $\mathrm{h}$} & $3.42 \pm 0.21$ & $3.40 \pm 0.26$ & 0.78 \\
\hline \multicolumn{2}{|c|}{ Duration of the pneumoperitoneum, $\mathrm{h}$} & $2.66 \pm 0.32$ & $2.61 \pm 0.43$ & 0.67 \\
\hline \multirow[t]{2}{*}{ Mean arterial pressure, $\mathrm{mm} \mathrm{Hg}$} & $\mathrm{T}_{1}$ & $80.09 \pm 11.10$ & $82.25 \pm 8.54$ & 0.28 \\
\hline & $\mathrm{T}_{2}$ & $80.52 \pm 10.13$ & $82.25 \pm 8.54$ & 0.55 \\
\hline \multirow[t]{2}{*}{ Heart rate, beats/min } & $\mathrm{T}_{1}$ & $72.43 \pm 10.20$ & $72.25 \pm 7.67$ & 0.94 \\
\hline & $\mathrm{T}_{2}$ & $74.35 \pm 10.52$ & $76.15 \pm 7.30$ & 0.51 \\
\hline \multirow[t]{2}{*}{$\mathrm{AaDO}_{2}$} & $\mathrm{~T}_{1}$ & $129.12 \pm 36.06$ & $155.57 \pm 29.58$ & 0.02 \\
\hline & $\mathrm{T}_{2}$ & $123.57 \pm 29.58$ & $143.36 \pm 26.82$ & 0.03 \\
\hline
\end{tabular}

$\mathrm{AaDO}_{2}$, arterial-to-alveolar oxygenation gradient; $\mathrm{V}_{\mathrm{T}}$, tidal volume; PEEP, positive end-expiratory pressure; ZEEP, zero end-expiratory pressure; $\mathrm{T}_{1}, 60 \mathrm{~min}$ after a $40^{\circ}$ Trendelenburg position with pneumoperitoneum; $\mathrm{T}_{2}$, $120 \mathrm{~min}$ after a $40^{\circ}$ Trendelenburg position with pneumoperitoneum.

Hg, with da Vinci Robot Surgical System (Intuitive Surgical, Sunnyvale, CA, USA). Thereafter, the $40^{\circ}$ Trendelenburg position was established. Arterial blood gas analysis was performed preoperatively $\left(\mathrm{T}_{0}\right), 1 \mathrm{~h}$ after a $40^{\circ}$ Trendelenburg position with pneumoperitoneum $\left(\mathrm{T}_{1}\right), 2 \mathrm{~h}$ after a $40^{\circ}$ Trendelenburg position with pneumoperitoneum $\left(\mathrm{T}_{2}\right)$, and $24 \mathrm{~h}$ after the operation $\left(\mathrm{T}_{4}\right)$. Arterial-to-alveolar oxygenation gradients were calculated $60 \mathrm{~min}$ after a $40^{\circ}$ Trendelenburg position with pneumoperitoneum $\left(T_{1}\right)$ and $120 \mathrm{~min}$ after a $40^{\circ}$ Trendelenburg position with pneumoperitoneum $\left(\mathrm{T}_{2}\right)$.

The alveolar-to-arterial (A-a) oxygen gradient was the difference between the amount of the oxygen in the alveoli (i.e., the alveolar oxygen tension $\left[\mathrm{PAO}_{2}\right]$ ), and the amount of oxygen dissolved in plasma $\left(\mathrm{PaO}_{2}\right)$ was calculated as: $\mathrm{A}$-a oxygen gradient $=$ $\mathrm{PAO}_{2}-\mathrm{PaO}_{2}$.

$\mathrm{PaO}_{2}$ was measured by arterial blood gas, while $\mathrm{PAO}_{2}$ was calculated using the alveolar gas equation: $\mathrm{PAO}_{2}=\left(\mathrm{FiO}_{2} \times\left[\mathrm{P}_{\mathrm{atm}}-\right.\right.$ $\left.\left.\mathrm{P}_{\mathrm{H}_{2} \mathrm{O}}\right]\right)-\left(\mathrm{PaCO}_{2} / \mathrm{R}\right)$, where $\mathrm{F}_{\mathrm{i}} \mathrm{O}_{2}$ is the fraction of inspired oxygen, $\mathrm{P}_{\mathrm{atm}}$ is the atmospheric pressure, $\mathrm{P}_{\mathrm{H}_{2} \mathrm{O}}$ is the partial pressure of water, $\mathrm{PaCO}_{2}$ is the arterial carbon dioxide tension, and $\mathrm{R}$ is the respiratory quotient.

At the 24th hour of surgery, chest X-ray and spirometric testing were repeated. Spirometric testing was only performed if NRS scores at rest were lower than 3 . If not, the pain was relieved before spirometric measurements. Three measurements of FVC, $\mathrm{FEV}_{1}$, and peak expiratory flow rate (PEF) were done, and the highest values were taken into consideration for statistical analysis.

Pre- and postoperative chest X-rays were evaluated using the radiological atelectasis score (RAS) [9] (with a 5-point scale) by a single radiologist who was blinded to this study as follows: clear lung fields, 0; plate-like atelectasis or slight infiltration, 1; partial atelectasis, 2; lobar atelectasis, 3; and bilateral atelectasis, 4 .

Statistical Analysis

Statistical analysis was performed using MedCalc Statistical Software version 12.7.7 (MedCalc Software bvba, Ostend, Belgium; http://www.medcalc.org). The normality of continuous variables was investigated using the Shapiro-Wilk test. Descriptive statistics are presented as means \pm SD for normally distributed variables and medians (IQR) (25th to 75th percentile) for nonnormally distributed variables. Student's $t$ test was used for comparisons of 2 normally distributed groups. Nonparametric statistical methods were used for values with a skewed distribution. For comparison of 2 nonnormally distributed groups, the Mann-Whitney U test was used. Dependent and nonnormally distributed continuous variables were analyzed using the Wilcoxon signed-rank test. $p<0.05$ was considered statistically significant.

\section{Results}

All operations were performed without complications and without conversion to an open technique. The baseline characteristics of the patients and the operative data are presented in Table 1. There were no significant differences between the 2 groups in terms of patient characteristics or hemodynamic variables. Overall the pneumoperitoneum duration was $2.66 \pm 0.32 \mathrm{~h}$ in the low $\mathrm{V}_{\mathrm{T}}$-ZEEP group and $2.61 \pm 0.43 \mathrm{~h}$ in the high $\mathrm{V}_{\mathrm{T}}$-PEEP group. At all times, the arterial-to-alveolar oxygenation gradients were significantly lower in the low $\mathrm{V}_{\mathrm{T}}$-PEEP group than in the high $\mathrm{V}_{\mathrm{T}}$-ZEEP group ( $p=0.02$ and $p=0.03$, respectively). Intraoperative and postoperative $\mathrm{PaO}_{2}$ and $\mathrm{SaO}_{2}$ values were significantly higher in the low $\mathrm{V}_{\mathrm{T}}$-PEEP group than in the high $\mathrm{V}_{\mathrm{T}}$-ZEEP group (Table 2 ).

A comparison of the spirometric measurements is presented in Table 3. The preoperative FVC, $\mathrm{FEV}_{1}$, and $\mathrm{PEF}$ values were similar between the 2 groups (i.e., 92.5 vs. 91; 
Table 2. Arterial blood gases of the patients

\begin{tabular}{|c|c|c|c|c|}
\hline & & $\begin{array}{l}\text { Low } \mathrm{V}_{\mathrm{T}} \text {-PEEP } \\
(n=24)\end{array}$ & $\begin{array}{l}\text { High } \mathrm{V}_{\mathrm{T}}-\text { ZEEP } \\
(n=20)\end{array}$ & $p$ value \\
\hline \multirow[t]{5}{*}{$\mathrm{pH}$} & $\mathrm{T}_{0}$ & $7.38 \pm 0.03$ & $7.37 \pm 0.03$ & 0.85 \\
\hline & $\mathrm{T}_{1}$ & $7.25 \pm 0.04$ & $7.25 \pm 0.03$ & 1.0 \\
\hline & $\mathrm{T}_{2}$ & $7.25 \pm 0.03$ & $7.23 \pm 0.05$ & 0.93 \\
\hline & $\mathrm{T}_{3}$ & $7.33 \pm 0.05$ & $7.32 \pm 0.03$ & 0.78 \\
\hline & $\mathrm{T}_{4}$ & $7.38 \pm 0.05$ & $7.38 \pm 0.04$ & 1.0 \\
\hline \multirow[t]{5}{*}{$\mathrm{PaCO}_{2}, \mathrm{~mm} \mathrm{Hg}$} & $\mathrm{T}_{0}$ & $36.17 \pm 3.14$ & $36.88 \pm 2.88$ & 0.21 \\
\hline & $\mathrm{T}_{1}$ & $48.04 \pm 4.92$ & $49.96 \pm 3.51$ & 0.07 \\
\hline & $\mathrm{T}_{2}$ & $49.35 \pm 4.82$ & $52.98 \pm 8.22$ & 0.06 \\
\hline & $\mathrm{T}_{3}$ & $37.55 \pm 5.58$ & $38.41 \pm 4.38$ & 0.28 \\
\hline & $\mathrm{T}_{4}$ & $35.62 \pm 3.94$ & $36.52 \pm 3.68$ & 0.21 \\
\hline \multirow[t]{5}{*}{$\mathrm{PaO}_{2}, \mathrm{~mm} \mathrm{Hg}$} & $\mathrm{T}_{0}$ & $89.68 \pm 14.97$ & $82.37 \pm 8.82$ & 0.97 \\
\hline & $\mathrm{T}_{1}$ & $179.33 \pm 33.94$ & $150.97 \pm 34.27$ & 0.009 \\
\hline & $\mathrm{T}_{2}$ & $184.88 \pm 30.45$ & $160.15 \pm 27.34$ & 0.008 \\
\hline & $\mathrm{T}_{3}$ & $85.01 \pm 16.89$ & $70.62 \pm 11.70$ & 0.003 \\
\hline & $\mathrm{T}_{4}$ & $77.68 \pm 16.86$ & $65.09 \pm 15.21$ & 0.014 \\
\hline \multirow[t]{5}{*}{$\mathrm{HCO}_{3}, \mathrm{meq} / \mathrm{L}$} & $\mathrm{T}_{0}$ & $22.12 \pm 1.70$ & $21.60 \pm 1.74$ & 0.83 \\
\hline & $\mathrm{T}_{1}$ & $19.73 \pm 1.87$ & $19.96 \pm 1.39$ & 0.32 \\
\hline & $\mathrm{T}_{2}$ & $19.70 \pm 1.64$ & $19.67 \pm 1.68$ & 0.52 \\
\hline & $\mathrm{T}_{3}$ & $19.79 \pm 1.85$ & $19.91 \pm 1.67$ & 0.41 \\
\hline & $\mathrm{T}_{4}$ & $22.08 \pm 2.11$ & $22.34 \pm 2.54$ & 0.35 \\
\hline \multirow[t]{5}{*}{$\mathrm{BE}$} & $\mathrm{T}_{0}$ & $-2.80 \pm 2.06$ & $-3.35 \pm 2.28$ & 0.79 \\
\hline & $\mathrm{T}_{1}$ & $-5.35 \pm 3.27$ & $-5.34 \pm 1.83$ & 0.49 \\
\hline & $\mathrm{T}_{2}$ & $-6.00 \pm 2.33$ & $-5.36 \pm 3.03$ & 0.21 \\
\hline & $\mathrm{T}_{3}$ & $-5.67 \pm 2.46$ & $-5.39 \pm 2.20$ & 0.34 \\
\hline & $\mathrm{T}_{4}$ & $-2.40 \pm 3.01$ & $-2.50 \pm 3.26$ & 0.54 \\
\hline \multirow[t]{5}{*}{$\mathrm{SaO}_{2}, \%$} & $\mathrm{~T}_{0}$ & $97.54 \pm 1.08$ & $97.03 \pm 1.13$ & 0.93 \\
\hline & $\mathrm{T}_{1}$ & $99.29 \pm 0.45$ & $98.67 \pm 0.64$ & 0.001 \\
\hline & $\mathrm{T}_{2}$ & $99.25 \pm 0.62$ & $98.78 \pm 0.60$ & 0.016 \\
\hline & $\mathrm{T}_{3}$ & $96.47 \pm 2.04$ & $93.77 \pm 3.47$ & 0.007 \\
\hline & $\mathrm{T}_{4}$ & $96.12 \pm 2.33$ & $93.71 \pm 2.62$ & 0.003 \\
\hline
\end{tabular}

$\mathrm{pH}$, potential of hydrogen; $\mathrm{PaCO}_{2}$, arterial carbon dioxide pressure; $\mathrm{PaO}_{2}$, arterial oxygen pressure; $\mathrm{HCO}_{3}$, bicarbonate; $\mathrm{BE}$, base excess; $\mathrm{SaO}_{2}$, arterial oxygen saturation; $\mathrm{T}_{0}$, preoperative; $\mathrm{T}_{1}, 60$ min after a $40^{\circ}$ Trendelenburg position with pneumoperitoneum; $\mathrm{T}_{2}, 120 \mathrm{~min}$ after a $40^{\circ}$ Trendelenburg position with pneumoperitoneum; $\mathrm{T}_{3}, 2 \mathrm{~h}$ after the operation; $\mathrm{T}_{4}, 24 \mathrm{~h}$ after the operation.

99 vs. 98.5 ; and 93.5 vs. 91.5 , respectively). A significant reduction in $\mathrm{FVC}, \mathrm{FEV}_{1}$, and PEF was recorded postoperatively in both groups $(p<0.001)$. However, postoperative $\mathrm{FVC}, \mathrm{FEV}_{1}$, and PEF values were significantly lower in the high $\mathrm{V}_{\mathrm{T}}$-ZEEP group than in the low $\mathrm{V}_{\mathrm{T}}$-PEEP group $(p<0.001)$.

The pain significantly decreased over time in all groups after surgery. NRS scores and morphine consumption were similar between the 2 groups (Table 4 ).
Preoperative RAS were similar in both groups, but the postoperative RAS was significantly lower in the low $\mathrm{V}_{\mathrm{T}^{-}}$ PEEP group than in the high $\mathrm{V}_{\mathrm{T}}$-ZEEP group $(p<0.001)$ (Table 5).

\section{Discussion}

In this RALP study, postoperative pulmonary functions were less impaired in patients ventilated with $6 \mathrm{~mL} /$ $\mathrm{kg} \mathrm{V}_{\mathrm{T}}$ and $8 \mathrm{~cm} \mathrm{H}_{2} \mathrm{O}$ PEEP than in those ventilated with $10 \mathrm{~mL} / \mathrm{kg} \mathrm{V}_{\mathrm{T}}$ and ZEEP. No patient experienced intraoperative respiratory complications, but intraoperative oxygenation was significantly reduced in patients ventilated with a high $\mathrm{V}_{\mathrm{T}}$-ZEEP than in those with a low $\mathrm{V}_{\mathrm{T}}$-PEEP and there were no differences in $\mathrm{ETCO}_{2}, \mathrm{PAP}$, or hemodynamic parameters. In the postoperative period, although significant reductions in $\mathrm{FVC}, \mathrm{FEV}_{1}, \mathrm{PEF}$, and partial arterial oxygen concentrations were observed in both groups, the reductions were smaller in the low $\mathrm{V}_{\mathrm{T}^{-}}$ PEEP group compared to the high $\mathrm{V}_{\mathrm{T}}$-ZEEP group.

In this study, the $\mathrm{PaO}_{2}$ and $\mathrm{SaO}_{2}$ values of the patients were significantly lower in the high $\mathrm{V}_{\mathrm{T}}$-ZEEP group compared to the low $\mathrm{V}_{\mathrm{T}}$-PEEP group, whereas the intraoperative A-a $\left(\mathrm{DO}_{2}\right)$ was lower in the low $\mathrm{V}_{\mathrm{T}}$-PEEP group. Intraoperative oxygenation was significantly reduced in patients ventilated with a high $\mathrm{V}_{\mathrm{T}}$-ZEEP than those with a low $\mathrm{V}_{\mathrm{T}}$-PEEP. The significance remained constant during the first $24 \mathrm{~h}$. These results favor the use of $6 \mathrm{~mL} / \mathrm{kg} \mathrm{V}_{\mathrm{T}}$ and $8 \mathrm{~cm} \mathrm{H}_{2} \mathrm{O}$ PEEP during RALP. There is some evidence for the benefits of intraoperative lung protective ventilation both in thoracic and in major abdominal [9-13] and laparoscopic surgeries [14]. The major difference in RALP versus other laparoscopic surgeries is the sT positioning. Pulmonary pathophysiological effects of sT positioning together with pneumoperitoneum include further decreases in functional residual capacity, compliance, and vital capacity resulting in an altered gas exchange. Prevention of these unwanted effects requires intraoperative use of PEEP. The recommended PEEP level remains over $5 \mathrm{~cm}$ $\mathrm{H}_{2} \mathrm{O}$ in patients undergoing laparoscopic surgery [15], but the optimal level of PEEP has not yet been determined in the sT position by earlier studies. According to our study, $8 \mathrm{~cm} \mathrm{H} \mathrm{H}_{2} \mathrm{O}$ might be the optimal level of PEEP for patients undergoing laparoscopic surgery with sT positioning.

Although the $\mathrm{PaO}_{2}$ decreased significantly in the postoperative period in both groups, at the 24th $\mathrm{h}$ it returned to preanesthetic values in the low $\mathrm{V}_{\mathrm{T}}$-PEEP group, indicating the benefits of moderate PEEP. Even though patients in the low $\mathrm{V}_{\mathrm{T}}$-PEEP group had fewer decreases in 
Table 3. Comparison of spirometric measurements

\begin{tabular}{llccc}
\hline & & $\begin{array}{l}\text { Low } \mathrm{V}_{\mathrm{T}} \text {-PEEP } \\
(n=24)\end{array}$ & $\begin{array}{l}\text { High } \mathrm{V}_{\mathrm{T}} \text {-ZEEP } \\
(n=20)\end{array}$ & $p$ value \\
\hline \multirow{2}{*}{ FVC } & preoperative & $92.5(86-97)$ & $91(87.75-94.5)$ & 0.500 \\
& postoperative & $64(57-68)$ & $51(45.75-54)$ & $<0.001$ \\
& $p$ & $<0.001$ & 0.001 & 0.849 \\
\hline FEV & preoperative & $99(97-103)$ & $98.5(96.25-103.75)$ & $<0.001$ \\
& postoperative & $70(67.25-77.75)$ & $54.5(44.25-57)$ & 0.768 \\
& $p$ & $<0.001$ & 0.001 & $<0.001$ \\
\hline PEF & preoperative & $93.5(90-96.5)$ & $91.5(87.5-98.5)$ & \\
& postoperative & $65.5(60-70)$ & $44.5(40.5-4775)$ & $<0.001$ \\
\hline
\end{tabular}

Values are medians and IQR (25th to 75th percentiles) unless otherwise stated. $\mathrm{V}_{\mathrm{T}}$, tidal volume; PEEP, positive end-expiratory pressure; ZEEP, zero end-expiratory pressure; FVC, forced vital capacity; $\mathrm{FEV}_{1}$, forced expiratory volume in $1 \mathrm{~s}$; PEF, peak expiratory flow rate.

Table 4. NRS scores and total morphine consumption

\begin{tabular}{lcrlrl}
\hline & $\begin{array}{l}\text { NRS score } \\
\text { at } 2 \mathrm{~h}\end{array}$ & $\begin{array}{l}\text { NRS score } \\
\text { at } 6 \mathrm{~h}\end{array}$ & $\begin{array}{l}\text { NRS score } \\
\text { at } 18 \mathrm{~h}\end{array}$ & $\begin{array}{l}\text { NRS score } \\
\text { at } 24 \mathrm{~h}\end{array}$ & $\begin{array}{l}\text { Total morphine } \\
\text { consumption, mg }\end{array}$ \\
\hline $\begin{array}{l}\text { Low } \mathrm{V}_{\mathrm{T}} \text {-PEEP } \\
\begin{array}{l}n=24) \\
\text { High } \mathrm{V}_{\mathrm{T}} \text {-ZEEP } \\
(n=20)\end{array}\end{array}$ & $2(2-3)$ & $2(2-3)$ & $1(1-3)$ & $1(0-2)$ & $20(18-25)$ \\
$p$
\end{tabular}

Values are presented as medians (range) unless otherwise stated. NRS, numerical rating scale; $\mathrm{V}_{\mathrm{T}}$, tidal volume; PEEP, positive end-expiratory pressure; ZEEP, zero end-expiratory pressure.

$\mathrm{PaO}_{2}$, the decreases in the postoperative $\mathrm{PaO}_{2}$ in both groups should remind us that PEEP alone did not have a long-lasting effect. Thus, application of PEEP or CPAP after surgery might be an alternative approach to preventing decreases in postoperative oxygenation $[13,16]$.

Pulmonary function testing is valuable in predicting postoperative pulmonary complications, especially atelectasis [17]. FVC, $\mathrm{FEV}_{1}$, and PEF were significantly decreased in the postoperative period in both groups, but the values measured were in the normal ranges in the low $\mathrm{V}_{\mathrm{T}}$-PEEP group. The decreases in FVC, $\mathrm{FEV}_{1}$, and PEF were significantly lower in the low $\mathrm{V}_{\mathrm{T}}$-PEEP group compared to the high $\mathrm{V}_{\mathrm{T}}$-ZEEP group, emphasizing the benefit of PEEP application in the intraoperative period of RALP. Kilic et al. [18] stated that postoperative vital capacity and $\mathrm{FEV}_{1}$ values were reduced in patients without COPD, returning to normal levels only after 5 days. In our patients, we measured pulmonary functions at the 24 th postoperative hour.

Mechanical Ventilation in Robot-Assisted Surgery
Table 5. Comparison of RAS between groups

\begin{tabular}{lcc}
\hline & Preoperative RAS & \multicolumn{1}{c}{$\mathrm{D}_{1}$ RAS } \\
\hline $\begin{array}{l}\text { Low } \mathrm{V}_{\mathrm{T}} \text {-PEEP } \\
(n=24)\end{array}$ & $0(0-1)$ & $1(1-2)$ \\
$\begin{array}{l}\text { High } \mathrm{V}_{\mathrm{T}} \text {-ZEEP } \\
(n=20)\end{array}$ & $0.5(0-1)$ & $3(2-3)$ \\
$p$ & 0.989 & $<0.001$ \\
\hline
\end{tabular}

Values are presented as medians (range) unless otherwise stated. RAS, radiological atelectasis score; $\mathrm{D}_{1}$, day $1 ; \mathrm{V}_{\mathrm{T}}$, tidal volume; PEEP, positive end-expiratory pressure; ZEEP, zero end-expiratory pressure.

The limitations of this study included that: we did not measure the intraoperative functional residual capacity and compliance; we did not ensure that atelectasis was not underdiagnosed on the chest X-ray; the postoperative evaluation of pulmonary functions was limited to the first $24 \mathrm{~h}$. 


\section{Conclusion}

In this study, patients ventilated with a high $\mathrm{V}_{\mathrm{T}}$ and ZEEP were more prone to the unwanted effects of combined sT positioning and pneumoperitoneum in RALP compared to patients ventilated with a low $\mathrm{V}_{\mathrm{T}}$ and moderate PEEP.

\section{Acknowledgement}

We thank to Dr. Ahmet Yanlı for evaluating the chest X-rays to measure RAS.

\section{Disclosure Statement}

None.

\section{References}

1 Jemal A, Siegel R, Xu J, et al: Cancer statistics, 2010. CA Cancer J Clin 2010;60:277-300.

2 Trinh QD, Sammon J, Sun M, et al: Perioperative outcomes of robot-assisted radical prostatectomy compared with open radical prostatectomy: results from the nationwide inpatient sample. Eur Urol 2012;61:679-685.

3 Guru KA, Hussain A, Chandrasekhar R, et al: Current status of robot-assisted surgery in urology: a multi-national survey of 297 urologic surgeons. Can J Urol 2009;16:47364741.

4 Murphy DG, Bjartell A, Ficarra V, et al: Downsides of robot-assisted laparoscopic radical prostatectomy: limitations and complications. Eur Urol 2010;57:735-746.

5 Menon M, Tewari A, Baize B, et al: Prospective comparison of radical retropubic prostatectomy and robot-assisted anatomic prostatectomy: the Vattikuti Urology Institute experience. Urology 2002;60:864-868.

6 Kalmar AF, Foubert L, Hendrickx JF, et al: Influence of steep Trendelenburg position and $\mathrm{CO}_{2}$ pneumoperitoneum on cardiovascular, cerebrovascular, and respiratory homeostasis during robotic prostatectomy. $\mathrm{Br} J$ Anaesth 2010;104:433-439.
7 Lestar M, Gunnarsson L, Lagerstrand L, et al: Hemodynamic perturbations during robotassisted laparoscopic radical prostatectomy in 45 degrees Trendelenburg position. Anesth Analg 2011;113:1069-1075.

8 Rangel-Frausto MS, Pittet D, Costigan M, et al: The natural history of the systemic inflammatory response syndrome (SIRS): a prospective study. JAMA 1995;273:117-123.

$9 \mathrm{Gu}$ W-J, Wang F, Liu JC: Effect of lung-protective ventilation with lower tidal volumes on clinical outcomes among patients undergoing surgery: a meta-analysis of randomized controlled trials. CMAJ 2015;187:E101-E109.

10 Tao T, Bo L, Chen F, et al: Effect of protective ventilation on postoperative pulmonary complications in patients undergoing general anaesthesia: a meta-analysis of randomised controlled trials. BMJ Open 2014;4:e005208.

11 Futier E, Jaber S: Lung-protective ventilation in abdominal surgery. Curr Opin Crit Care 2014;20:426-430.

12 Schultz MJ, Abreu MG, Pelosi P: Mechanical ventilation strategies for the surgical patient. Curr Opin Crit Care 2015;21:351-357.

13 Park SH: Perioperative lung-protective ventilation strategy reduces postoperative pulmonary complications in patients undergoing thoracic and major abdominal surgery. Korean J Anesthesiol 2016;69:3-7.
14 Park SJ, Kim BG, Qh AH, et al: Effects of intraoperative protective lung ventilation on postoperative pulmonary complications in patients with laparoscopic surgery: prospective, randomized and controlled trial. Surg Endosc 2016;30:4598-4606

15 Futier E, Constantin JM, Pelosi P, et al: Intraoperative recruitment maneuver reverses detrimental pneumoperitoneum-induced respiratory effects in healthy weight and obese patients undergoing laparoscopy. Anesthesiology 2010;113:1310-1319.

16 Ferrando C, Soro M, Canet J, et al: Rationale and study design for an Individualized Perioperative Open Lung Ventilatory Strategy (iPROVE): study protocol for a randomized controlled trial. Trials 2015;16:193.

17 Lindberg P, Gunnarsson L, Tokics L, et al: Atelectasis and lung function in the postoperative period. Acta Anaesthesiol Scand 1992;36: 546-553.

18 Kilic OF, Börgers A, Köhne W, et al: Effects of steep Trendelenburg position for roboticassisted prostatectomies on intra- and extrathoracic airways in patients with or without chronic obstructive pulmonary disease. Br J Anaesth 2015;114:70-76. 